University of Nebraska - Lincoln

DigitalCommons@University of Nebraska - Lincoln

Faculty Publications, Department of Psychology

Psychology, Department of

2000

\title{
Antipredator vigilance of juvenile and adult thirteen-lined ground squirrels and the role of nutritional need
}

\section{Cody Arenz}

University of Nebraska-Lincoln

Daniel Leger

University of Nebraska-Lincoln, dleger1@unl.edu

Follow this and additional works at: https://digitalcommons.unl.edu/psychfacpub

Part of the Psychiatry and Psychology Commons

Arenz, Cody and Leger, Daniel, "Antipredator vigilance of juvenile and adult thirteen-lined ground squirrels and the role of nutritional need" (2000). Faculty Publications, Department of Psychology. 480.

https://digitalcommons.unl.edu/psychfacpub/480

This Article is brought to you for free and open access by the Psychology, Department of at DigitalCommons@University of Nebraska - Lincoln. It has been accepted for inclusion in Faculty Publications, Department of Psychology by an authorized administrator of DigitalCommons@University of Nebraska - Lincoln. 


\title{
Antipredator vigilance of juvenile and adult thirteen-lined ground squirrels and the role of nutritional need
}

\author{
Cody L. Arenz ' and Daniel W. Leger ${ }^{2}$ \\ I. Nebraska Behavioral Biology Group, School of Biological Sciences, University of Nebraska-Lincoln \\ 2. Nebraska Behavioral Biology Group, Department of Psychology, University of Nebraska-Lincoln \\ Corresponding author - C. L. Arenz; Present address: Biology Department, Nebraska Wesleyan University, \\ 5000 St Paul Avenue, Lincoln, NE 68504, U.S.A.; e-mail carenz@nebrwesleyan.edu
}

\begin{abstract}
Juvenile thirteen-lined ground squirrels, Spermophilus tridecemlineatus, are less vigilant (i.e. they spend less time visually scanning the environment) than adults. To determine whether nutritional need was a potential cause of this difference, we supplemented two groups of free-ranging juveniles during the predispersal stage, while juveniles were still near and around the natal burrows. The high-energy food group (HEF: 11 squirrels) received peanut butter and oats while the low-energy food group (LEF: seven squirrels) received lettuce. Adults (14 squirrels) were also supplemented, but due to their greater home range sizes, it was not feasible to classify them as either HEF or LEF. To evaluate the effect of supplementation on antipredator vigilance, the behavioral act of visually scanning for predators, we videotaped individuals while they were foraging above ground during 5-min observation periods. Each squirrel was observed and weighed during three time periods over 23 days. From the videotape, we extracted measures of time spent vigilant, locomoting and foraging. All three categories of squirrels gained mass over the study period, but the HEF juveniles rapidly exceeded that of the LEF juveniles. Early in the study, LEF and HEF juveniles did not significantly differ in either body mass or time budgets, and, initially, both juvenile groups were similar to adults in the amount of time devoted to vigilance. Later in the study, the behavior of HEF juveniles closely resembled that of adults (increased time devoted to vigilance and decreased time devoted to foraging), while LEF juveniles decreased vigilance and increased their foraging time. This study indicates that for thirteen-lined ground squirrels the lower vigilance of juveniles is due, at least in part, to the greater nutritional needs of young animals with consequent increases in foraging, which is largely incompatible with vigilance.
\end{abstract}

Juvenile mammals often experience higher mortality rates than do adults (Rongstad 1965; McCarley 1966; Sibly et al. 1997). Sibly et al. (1997) presented mortality data for mammals indicating that the mortality of juvenile rodents is significantly higher than that of either young or old adults. This difference in mortality risk could result in agerelated differences in behavior of juveniles and adults, such as antipredator vigilance (i.e. visual scanning in ways that would tend to increase the detection of predators; Loughry 1992; Burger \& Gochfeld 1994; Arenz \& Leger 1997).

Although differences in mortality rates may be due to other factors, predation is an important source of mortality for juvenile mammals (e.g. Rongstad 1965; McCarley 1966). Therefore, one might expect that juveniles would be particularly vigilant for predators. However, a survey of the literature (see Table 1) revealed that, of 22 mammalian species examined for an age effect on antipredator vigilance, juveniles were less vigilant than the adults in 11 species; in only two species were juveniles more vigilant than adults. In the remaining nine, there were no differences, or the evidence was equivocal.

There are varied reasons for the lack of an age-related difference in vigilance in the other nine species. In the armadillo, Dasypus novemcinctus, no age effect was found and the authors concluded that the vigilance was primarily directed at conspecifics during social interactions, but because vigilance varied positively with flight distance, there may also be antipredator benefits to vigilance (McDonough \& Loughry 1995). Bednekoff \& Ritter (1994) noted that juvenile springbok, Antidorcas marsupialis, are slightly less vigilant than adult females (using a dependent variable that excluded vigilance while walking), but found that both age classes spend nearly the same amount of time with their head raised (when including vigilance while walking). Carey \& Moore (1986) found that juvenile yellow-bellied marmots, Marmota flaviventris, are more vigilant than 
Table I. Mammalian species examined for age differences in antipredator vigilance

\begin{tabular}{|c|c|c|c|}
\hline Common name & Species & $\begin{array}{l}\text { Type of } \\
\text { effect noted }\end{array}$ & Source \\
\hline Impala & Aepyceros melampus & - Age effect* & Burger \& Gochfeld 1994 \\
\hline Springbok & Antidorcas marsupalis & No age effect & Bednekoff \& Ritter 1994 \\
\hline Spanish ibex & Capra pyrenaica & + Age effect & Alados 1985 \\
\hline Wedge-capped capuchin & Cebus olivaceus & +Age effect & De Ruiter 1986; Fragaszy 1990 \\
\hline Wildebeest & Connochaetes taurinus & +Age effect & Burger \& Gochfeld I 994 \\
\hline Black-tailed prairie dog & Cynomys ludovicianus & +Age effect & Loughry 1993 \\
\hline Fallow deer & Dama dama & No age effect & Schall \& Ropartz I985 \\
\hline Nine-banded armadillo & Dasypus novemcinctus & No age effect & McDonough \& Loughry 1995 \\
\hline Burchell's zebra & Equus burchelli & +Age effect & Burger \& Gochfeld 1994 \\
\hline Defassa waterbuck & Kobus defassa & +Age effect & Burger \& Gochfeld I 994 \\
\hline Uganda kob & Kobus kob & +Age effect & Burger \& Gochfeld I 994 \\
\hline African elephant & Loxodonta africana & No age effect & Burger \& Gochfeld 1994 \\
\hline \multirow[t]{2}{*}{ Eastern grey kangaroo } & Macropus giganteus & +Age effect & Heathcote 1987 \\
\hline & & No age effect & Colagross \& Cockburn 1993 \\
\hline Hoary marmot & Marmota caligata & -Age effect & Holmes $1984 \dagger$ \\
\hline Golden marmot & M. caudata & No age effect & Blumstein $1996 \dagger$ \\
\hline \multirow[t]{2}{*}{ Yellow-bellied marmot } & M. flaviventris & -Age effect & Carey \& Moore 1986 \\
\hline & & + Age effect & Armitage \& Chiesura 1994 \\
\hline Klipspringer & Oreotragus oreotragus & + Age effect & Tilson 1980 \\
\hline \multirow[t]{2}{*}{ Yellow baboon } & Papio cynocephalus & -Age effect $(+)$ & Alberts 1994 \\
\hline & & No age effect $(\hat{\jmath})$ & Alberts 1994 \\
\hline California ground squirrel & Spermophilus beecheyi & + Age effect & Loughry \& McDonough 1989 \\
\hline \multirow[t]{2}{*}{ Columbian ground squirrel } & S. columbianus & + Age effect & Betts 1976 \\
\hline & & +Age effect & MacHutchon \& Harestad 1990 \\
\hline Thirteen-lined ground squirrel & S. tridecemlineatus & +Age effect & Arenz \& Leger 1997 \\
\hline \multirow[t]{2}{*}{ African buffalo } & Syncerus caffer & -Age effect & Burger \& Gochfeld 1994 \\
\hline & & No age effect & Prins \& lason $1989 \ddagger$ \\
\hline
\end{tabular}

$*+/-$ Age effect: Positive/negative association between vigilance and age.

† Comparison of $\mathrm{I}$ - and 2-year-olds versus adults.

$\ddagger$ Confounded by time of day, group size, and position in group.

adults, but Armitage \& Chiesura (1994) found the opposite. Two other studies (Holmes 1984; Blumstein 1996) evaluated age differences in vigilance, but did not examine juveniles (young-of-the-year). Hoary marmot, Marmota caligata, yearlings look up more often than 2-year-olds or adults (Holmes 1984). In another sciurid, Marmota caudata, Blumstein (1996) compared the vigilance of yearlings and 2-year-olds to adults and did not detect an age effect.

Some of the disparity in the data above may reflect differences in the annual activity cycle at the time the data were collected. Loughry (1992) found that recently emerged, juvenile black-tailed prairie dogs, Cynomys ludovicianus, initially display greater vigilance than adults, but their vigilance later declines below that of the adults. This finding indicates that the stage of development may have a significant effect upon whether a difference in antipredator vigilance between juveniles and adults is found. However, the data collected thus far support the observation that juvenile mammals are often less vigilant than adults. Because age and antipredator vigilance generally covary positively, it is difficult to say whether juvenile mammals are at greater predation risk because of their lower vigilance, or due to some other factor such as dispersal, or lack of experience. However, recent evidence indicates that increased predation risk usually results in increased vigilance (Elgar
1989; Lima 1990; Quenette 1990; Roberts 1996); therefore, it might be surprising that juveniles in many species display lower levels of vigilance than adults, except that we know it is possible that juvenile and adult mammals differ on a wide number of variables such as foraging demands, tradeoffs between the risk of predation and starvation, and experience. Additionally, there is a relatively new theoretical perspective suggesting that differences between juveniles and adults have been viewed erroneously in the past. In short, juveniles should not be viewed merely as poor approximations of the well-adapted adult, but as developing through a series of adaptive stages (Alberts 1987; Hoffman et al. 1999). This ontogenetic adaptation perspective suggests, for example, that despite their greater risk of predation, juvenile mammals may be less vigilant than adults because they have been selected to forage intensely.

There are three main competing hypotheses for why juveniles might be less vigilant than adults. First, juveniles might need time to learn certain aspects of the behavior (e.g. when to perform it, how to perform it). Second, vigilance differences may be the result of a maturational effect. For example, because of their small size, juveniles may be harder for predators to detect and, therefore, juveniles may not need to be as vigilant as adults. In this paper, we have focused upon the testing of a third hypoth- 
esis. That is, that nutritional and energetic requirements differ between juveniles and adults, which would explain the previously observed positive relationship between age and vigilance (Arenz \& Leger 1997). Adult animals must obtain nutrients for maintenance and reproduction in the following year, and possibly migration or hibernation, but juveniles also need nutrients for these factors, and they need nutrients for growth.

In this study, we attempted to determine whether nutritional need is likely to be one of the causes underlying the vigilance difference between adult and juvenile thirteen-lined ground squirrels, Spermophilus tridecemlineatus (Arenz \& Leger 1997). Because it is possible that age-related changes could interact with nutritional intake, the results of this experiment cannot support or dismiss their potential effects (but see the Discussion). However, the literature contains evidence that foraging need can affect vigilance. For example, Metcalfe \& Furness (1984) found that the vigilance of nonmigratory, juvenile ruddy turnstones, Arenaria interpres, does not differ from that of adults during the wintering period, but is higher than that of the adults during the premigratory period. This suggests that the nutritional need of adults (in preparation for migration) reduces their ability to invest time in vigilance. Bachman (1993) showed that food-deprived juvenile Belding's ground squirrels, Spermophilus beldingi, display decreased vigilance in reaction to alarm calls relative to squirrels that have not been deprived food. Bachman argued that this trade-off between foraging and vigilance was due to nutritional need in the context of a long-term goal (growth and hibernation). However, no one has shown that food supplementation increases the vigilance of juvenile mammals or birds.

Using free-ranging, thirteen-lined ground squirrels, we compared the vigilance behavior of juveniles that were either supplemented with high-energy food (HEF) or lowenergy food (LEF). We did not make any comparisons between unsupplemented and unmanipulated juveniles. Adult ground squirrels were also supplemented, but their greater range of movement (e.g. some squirrels traveled more than $100 \mathrm{~m}$ to reach a HEF supplementation location) resulted in some degree of ambiguity as to which treatment condition particular squirrels experienced (i.e. HEF or LEF); therefore, the experimental groups or "squirrel categories" were HEF juveniles, LEF juveniles and adults. We tested the following predictions regarding the effects of age and supplementation condition upon antipredator vigilance: (1) adult vigilance would initially exceed that of the juveniles (Arenz \& Leger 1997); (2) after supplementation, HEF juveniles would display greater vigilance than LEF juveniles; and (3) over the duration of the study, the vigilance of HEF juveniles would approach that of the adults, but the vigilance of LEF juveniles would not.

\section{Methods}

\section{Study Site and Subjects}

Thirteen-lined ground squirrels are small (ca. 150- 200 g; $20-30 \mathrm{~cm}$ in length, including tail), burrowing, grassland rodents that occur across the Great Plains (Jones et al. 1985). Current suitable habitat includes human-managed areas such as cemeteries and parks, as well as pastures and roadside grassy areas (Higgins \& Stapp 1997). Thirteenlined ground squirrels are opportunistic omnivores and eat a wide variety of foods (Streubel \& Fitzgerald 1978). The squirrels eat some foods (e.g. dandelions, Taraxacum officinale) whilst on all fours, and others (e.g. earthworms) standing on two legs as they manipulate food items with their forepaws (C. L. Arenz, personal observation). Standing on two legs allows the squirrel both to consume food and to scan its surroundings for predators. This experiment was conducted at Wyuka Cemetery in Lincoln, Nebraska. The cemetery grounds (ca. $60.7 \mathrm{ha}$ ) primarily vary in the density of trees, graves and types of stones. Ground squirrels occur throughout the cemetery, but this study was confined to a ca. 8.1-ha area within which there was a somewhat lower density of trees which facilitated the behavioral observations. The gravestones in this area were flush with the ground, but there were many slender flower vases (ca. $16-28 \mathrm{~cm}$ high).

\section{Supplementation}

We trapped three or four individuals from each of eight separate litters (26 juveniles, 16 females and 10 males) and the spatially associated adults (14 individuals, $10 \mathrm{fe}-$ males and four males) near burrow entrances using Tomahawk ${ }^{\circledR}$ live-traps. We handled the squirrels using a cloth bag (Arenz 1997), marked them with nyanzol dye (Melchior \& Iwen 1965), and targeted them for supplementation. All adult females were parents. Four litters were randomly chosen to be supplemented HEF (a mixture of peanut butter and oats), while the other four litters were supplemented with LEF (lettuce). The purpose of high-energy supplementation was to reduce the foraging pressure on the HEF juveniles by increasing their mass. We created a LEF experimental group to serve as a control for activities involved in supplementation, as opposed to comparing to an unmanipulated group of juveniles. The litters appeared above ground 16-20 June 1998 and supplementation began on June 20,1998. Once per day, throughout the study, we placed either HEF (ca. $18 \mathrm{~g}$ per adult or juvenile squirrel) or LEF (ca. one-fourth head of lettuce per litter) near the natal burrows. All of the adults remained in the study area throughout the experiment, but eight of the juveniles (five males, three females) disappeared; therefore, the total number of juveniles completing the experiment was 18 .

To document potential changes in vigilance, we observed the above-ground behavior of all subjects within three periods: (1) June 22-28, designated as days 1-7 (the start of food supplementation); (2) June 29-July 3, designated as days 812; and (3) July 7-12, designated as days 13-18. The slight variation in the number of days per period was due to variation in time needed to observe and recapture the squirrels in our sample. We recaptured squirrels with live-traps during each time period and weighed them to the nearest $0.1 \mathrm{~g}$ on a battery-powered scale to assess the effects of supplementation condition upon body mass. 


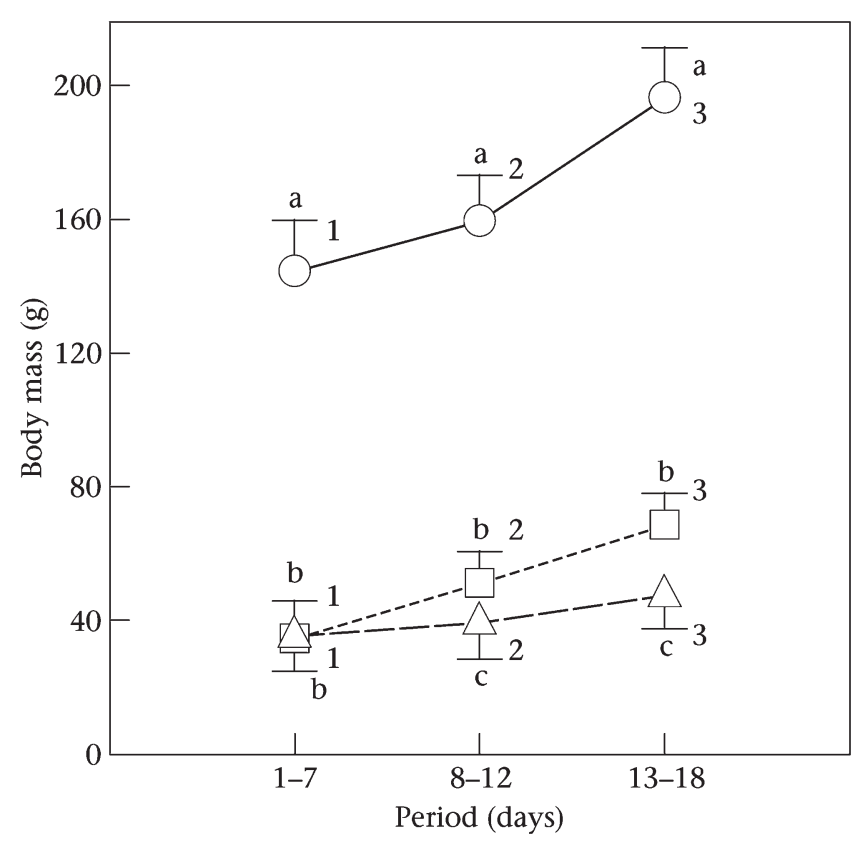

Figure I. Mean \pm SE body mass of adult ground squirrels $(\circ)$ and juvenile ground squirrels supplemented with high-energy $(\square)$ and low-energy $(\Delta)$ food across three sequential time periods, which approximate the days since juveniles first emerged from natal burrows. Letters indicate significant differences between squirrel categories (two-tailed $t$ tests: $P<0.05$ ) within a time period, while numbers indicate significant differences within a squirrel category (e.g. adults) across time periods.

\section{Procedure}

While seated in a vehicle, we opportunistically located squirrels (ca. 15-40 m between observer and subject). If we had been driving before spotting a subject, we waited 5 min before initiating a trial to ensure that the squirrels had resumed normal activity. All squirrels were engaged in above-ground foraging activity when observed. Some supplemental food was present during most of our data collection. This was because the LEF (lettuce) was not a preferred food and because we used large amounts of HEF. Although the supplemental food was usually present in the area during our observations, we avoided collecting data on squirrels that were feeding on these items. The behavior of the squirrels was recorded using a hand-held video camera. As in similar studies of other species (Leger et al. 1983), behaviors other than foraging, locomotion, or vigilance were uncommon, so our analysis is confined to these three categories. A videotaped observation period (or trial) was continuous up to $5 \mathrm{~min}$, but could be terminated early due to a disturbance (e.g. cemetery visitors nearby), agonistic interactions (one occurrence), losing sight of the squirrel above ground (eight occurrences), or if the squirrel went below ground (eight occurrences). Trials lasting less than $1 \mathrm{~min}$ prior to termination were deleted. We conducted a total of 110 trials, although 14 trials on squirrels that later disappeared were discarded (96 trials, $\vec{X}$ duration 4.3 min; number of trials on experimental groups: adult $=42$; $\mathrm{HEF}=33$; $\mathrm{LEF}=21$ ).
From the videotapes, we measured the amount of time the squirrels spent foraging (head down and nonlocomotory), in locomotion (walking and running) and vigilant (pausing in activity, except for chewing, and head above the shoulders). Vigilance behavior included four postures: (1) quadrupedal alert (all four feet on the ground with head above the horizontal); (2) semi-upright alert (on hind feet with a distinctive slouch); (3) upright alert (on hind feet with back straight and mostly perpendicular to the ground); (4) extended upright alert (similar to upright alert except that the squirrel extends its hind legs; Wistrand 1974). Our measure of vigilance combined all four postures; quadrupedal alerts accounted for the vast majority of total vigilance time. We measured the time spent foraging, in locomotion and vigilant to the nearest 0.10 $\mathrm{s}$, expressed as a percentage of total trial time.

\section{Statistical Analysis}

In this study, there were four supplemented litters and four unsupplemented litters. We used individual squirrels as our sampling unit based on three lines of reasoning. First, using logic similar to that of Leger \& Didrichsons (1994), we argue that if intralitter variation is greater than interlitter variation, then each squirrel's score can be considered an independent sample. The variation in scores within litters exceeded that between litters (1.97:1.0). Second, and consistent with our first point, we used one-way analysis of variance (ANOVA) to examine the possibility of litter effects within a supplementation condition for each time period and none was found (one-way ANOVA: all $F$ ratios $\ll 1.0, N S)$. Lastly, when we analyzed the data by litter, we obtained the same qualitative pattern, although several pairwise comparisons became nonsignificant due to the loss of statistical power.

We analyzed the data using SPSS version 5.0.1. For each dependent variable, we used three planned comparisons for each of the three time periods: adults versus HEF juveniles, adults versus LEF juveniles, and LEF juveniles versus $\mathrm{HEF}$ juveniles. To correct the alpha for an experiment-wise alpha of 0.05 , we evaluated each comparison at an alpha of 0.01 (Bonnferoni correction for directional hypotheses).

\section{Results}

\section{Body Mass}

All adults and juveniles increased in body mass over the course of the study (main effect of time period from mixed factorial ANOVA: $F_{2,56}=64.14, P<0.001$; Figure 1). All three squirrel categories contributed to this main effect (LEF juveniles, within-subjects ANOVA: $F_{2,12}=84.53, P<0.001$; HEF juveniles, within-subjects ANOVA: $F_{2,20}=151.74, P$ < 0.001; adults, within-subjects ANOVA: $F_{2,24}=33.99, P<$ $0.001)$. During days 8-12 and 13-18, juvenile ground squirrel body mass differed according to supplementation condition (two-tailed $t$ tests: $t_{16}=4.03$ and 6.18, respectively, $P$ $\leq$ 0.05; Figure 1), with HEF juveniles gaining weight more rapidly. Within an age class, no significant sex differences in mass were found; therefore, the masses of the two sexes were pooled into one estimate of the population mean. 

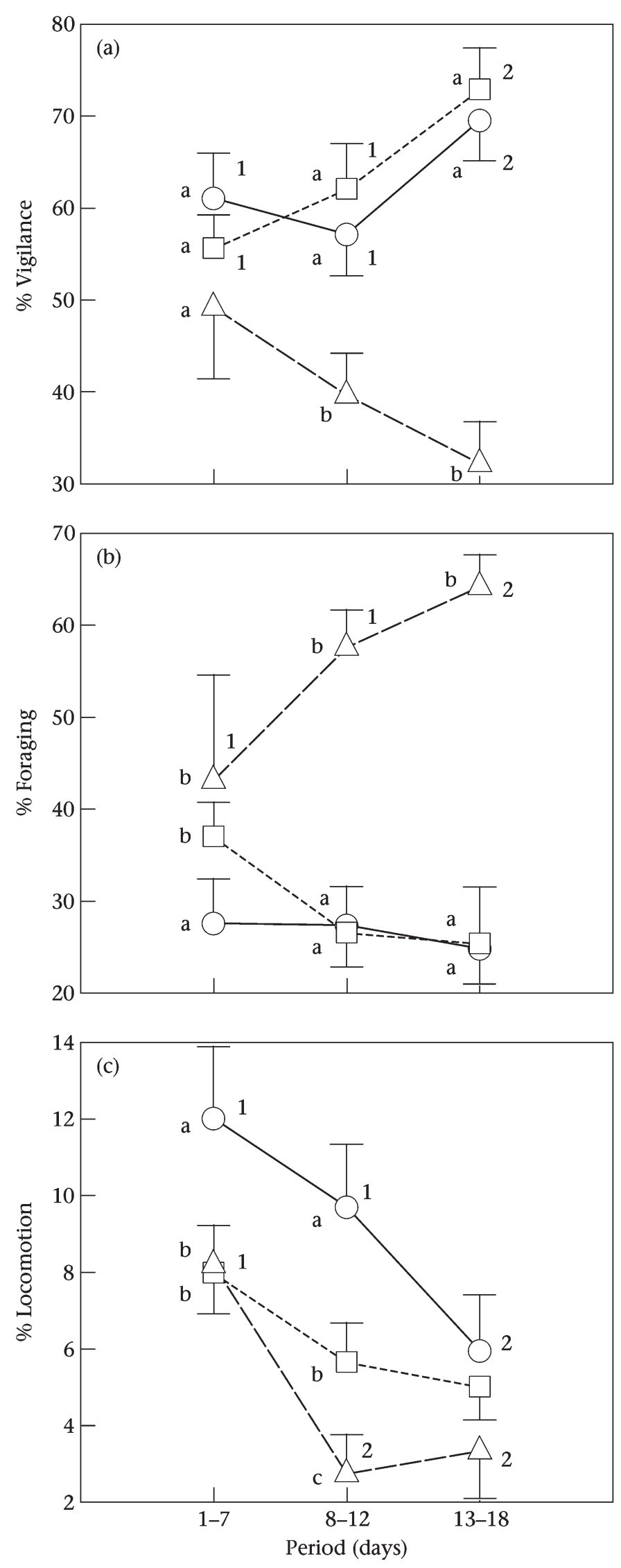

\section{Vigilance}

In general, HEF juveniles increased the percentage of time devoted to vigilance, while LEF juveniles decreased vigilance (Figure 2a). There was a main effect of squirrel category (mixed factorial ANOVA: percentage of time vigilant: $F_{2,29}=7.79, P=0.002$ ), but no significant effect of time period. The lack of a main effect of time period was due to the contrasting increasing and decreasing trends of the HEF and LEF juveniles (Figure 2a), as indicated by the significant interaction of squirrel category and time period (mixed factorial ANOVA: percentage of time vigilant: $F_{4,58}$ $=3.91, P=0.007$ ). During the first 2 days of supplementation, the percentage of time vigilant did not differ significantly between the squirrel categories (between-subjects ANOVA: $\left.F_{2,29}=0.91, P=0.41\right)$. Adult squirrels appeared to increase the amount of time devoted to vigilance over the three time periods (within-subjects ANOVA: $F_{2,26}=3.82, P$ $=0.035$, Figure 2a). During days 1-7, HEF and LEF juveniles did not differ significantly in their level of vigilance (two-tailed $t$ test of percentage of time vigilant: $t_{24}=0.94$, $P=0.35$ ), but the vigilance of HEF juveniles rapidly exceeded that of the LEF juveniles and became indistinguishable from adult vigilance by days 8-12 (two-tailed $t$ tests of percentage of time vigilant: HEF versus LEF: $t_{19}=3.16, P=$ 0.005; adult versus HEF: $t_{24}=0.42, P=0.68$ ). On the other hand, LEF juvenile vigilance showed a nonsignificant decreasing tendency over the three time periods (within-subjects ANOVA: $F_{2,12}=2.66, P=0.11$; Figure $2 \mathrm{a}$ ).

\section{Foraging and Locomotion}

The food supplementation affected the percentage of time devoted to foraging (main effect of squirrel category; mixed factorial ANOVA: $F_{2,29}=29.2, P \ll 0.001$ ), although foraging behavior did not differ significantly over time (main effect of time period; mixed factorial ANOVA: $\left.F_{2,58}=1.25, P=0.295\right)$. Supplementation condition and time period did not significantly interact for the percentage of time devoted to foraging (mixed factorial ANOVA: $F_{4,58}$ $=2.33, P=0.067)$. Adult ground squirrels did not significantly alter the percentage of time they devoted to foraging across the three time periods (two-tailed $t$ tests: NS). HEF juveniles appeared to decrease foraging, but there were no significant differences between time periods, and LEF juveniles increased the amount of time they devoted to foraging (days 8-12 versus days 13-18: two-tailed $t$ test: $t 6=$ 3.16, $P=0.020$; Figure 2b).

Figure 2. Mean \pm SE percentage of observation time devoted to (a) vigilance, (b) foraging and locomotion for adult ground squirrels $(\circ)$ and juvenile ground squirrels supplemented with high-energy $(\square)$ and low-energy $(\Delta)$ food across three sequential time periods. Letters indicate significant differences (two-tailed $t$ tests: $P<0.05$ ) within a time period, while numbers indicate significant differences within a squirrel category (e.g. adults) across time periods. The lack of a number or a letter indicates that no significant differences were detected. 
In general, there was a tendency for the percentage of time devoted to locomotion to decrease across time periods for all squirrel categories, but significant decreases were only present for adults and LEF juveniles (Figure 2c). The percentage of time devoted to locomotion varied significantly between the experimental groups (main effect of squirrel category; mixed factorial ANOVA: $F_{2,29}=3.83, P$ $=0.033$ ) and over time (main effect of time period; mixed factorial ANOVA: $F_{2.58}=5.26, P=0.008$ ); there was, however, no significant interaction between these factors (squirrel category $\times$ time period; mixed factorial ANOVA: $F_{4,58}=$ 1.54, $P=0.202)$.

\section{Discussion}

Juveniles of a variety of mammalian species are less vigilant than adults. Because juvenile mammals commonly display higher mortality rates than adults (Sibly et al. 1997), presumably due in part to predation, it is seemingly maladaptive for juveniles to be less vigilant. However, this opinion would be based upon seeing juveniles as approximations of the adult, instead of viewing these developmental stages as adaptive niches (ontogenetic adaptation: Alberts 1987). We tested the hypothesis that juvenile thirteen-lined ground squirrels are less vigilant than the adults because, at least in part, juveniles have a greater nutritional need. In other words, and in a classical tradeoff fashion (e.g. Sih 1980; Ydenberg \& Dill 1986), juveniles seem to be sacrificing some of their antipredator vigilance for increased foraging.

Arenz \& Leger (1997) found that thirteen-lined ground squirrel adults display greater vigilance than juveniles. At the start of the current study, juveniles and adults did not differ significantly in the percentage of time devoted to vigilance. This apparent discrepancy is due to Arenz \& Leger's (1997) observations corresponding to days 8-12 of this study, when we also noted age differences in vigilance. We hypothesized that this age difference in vigilance might exist because adults must forage to deposit fat for hibernation while juveniles must forage for both growth and fat deposition. Although vigilance conflicts with foraging (i.e. while scanning for predators, the squirrel's ability to search for food items is either absent or diminished), foraging and vigilance are not truly mutually exclusive, because squirrels can eat and scan simultaneously. However, increasing nutritional need is predicted to cause a decrease in vigilance, because the activities conflict. Consistent with this hypothesis, the HEF juveniles decreased foraging and increased vigilance while the LEF juveniles did not. In fact, the LEF juveniles showed a decreasing tendency in vigilance and increased foraging (Figure 2).

An interesting pattern of potential mortality was observed during this experiment. The number of marked juveniles decreased from 26 to 18 (two HEF and six LEF juveniles disappeared). Further research would be enlightening, but this suggests that HEF supplementation might have resulted in less mortality from predators, starvation, or disease; however, the difference was not statistically significant (Fisher's exact test: $P=0.202$ ).
Loughry (1992) observed juvenile, yearling and adult black-tailed prairie dogs and found that the vigilance of adults and yearlings exceed that of juveniles. At first emergence, prairie dog pups are more vigilant than individuals of other age classes and they gradually become less vigilant over a period of about 3 weeks. This pattern was not repeated here. We began supplementing thirteen-lined ground squirrel juveniles with food soon after pup emergence and the juveniles displayed the same level of vigilance as the adults from the onset. However, as mentioned above, the LEF juveniles decreased vigilance over the relatively short duration of the study. In similar contrast to our data, Loughry (1992) found that prairie dog pups at first emergence feed less than adults, but later devote more time to feeding than adults. Loughry (1993) duplicated these results, but reported that yearlings are intermediate on all behaviors and statistically indistinguishable from either adults or juveniles.

All thirteen-lined ground squirrel subjects gained mass over time (Figure 1). However, HEF juvenile mass was greater than that of LEF juveniles. Although we did not compare LEF juveniles with unsupplemented juveniles, it is unlikely that this difference in mass gain is due to some detrimental effect of lettuce, as we never saw any squirrel do more than briefly 'sample' the lettuce supplement. Except for the food quality, both HEF and LEF juveniles were treated the same in this experiment, which leads us to conclude that nutritional need influences juvenile ground squirrel vigilance. While an interaction between nutritional need and other factors such as learning are possible, this interaction is unlikely to be the cause of the observed effect, based on our observation that juveniles displayed adult-level vigilance at the beginning of the study.

Within age classes, no sexual differences in mass were found. Primarily for juveniles, this may be due to the relatively short duration of this study (23 days of supplementation). Evans (1951) weighed juvenile thirteen-lined ground squirrels over a period of about 45 days, at a later stage of development, and concluded that juvenile males appeared to gain mass more rapidly than juvenile females.

We found no sex differences in vigilance, time devoted to locomotion, or feeding for thirteen-lined ground squirrel adults or juveniles. Our data contrast with those of Holekamp \& Nunes (1989) who found that male and female California ground squirrels, Spermophilus beecheyi, of both age classes differ in their time budgets. However, we believe that the primary reason for the disparity between the two data sets is that Holekamp \& Nunes (1989) measured these variables over 10 months, thereby increasing the likelihood of detecting sex differences.

A classic argument for why young animals may differ in their behavior from adults is that they must learn how and when to perform the behavior. This study is important because it suggests that, although learning and maturational effects may be present, nutritional need can explain why juvenile thirteen-lined ground squirrels are normally less vigilant than adults. 


\section{Acknowledgments}

This study was made possible by a NSF Dissertation Improvement Grant (no. IBN-9701137). We thank Gwen Bachman for help with the manuscript. Steffi Jesseau's enthusiastic research assistance was greatly appreciated. We thank Michael Hutchinson and Wyuka Cemetery for allowing us to use their grounds. This research was approved by the University of Nebraska IACUC on 6 February 1996 under IACUC No. 96-01-005.

\section{References}

Alados, C. L. 1985. An analysis of vigilance in the Spanish ibex (Capra pyrenaica). Zeitschrift für Tierpsychologie, 68, 58-64.

Alberts, J. R. 1987. Early learning and ontogenetic adaptation. In: Perinatal Development: a Psychobiological Perspective (Ed. by N. A. Krasnegor, E. M. Blass, M. A. Hofer, and W. P. Smotherman), pp. I I-37. New York: Academic Press.

Alberts, S. C. 1994. Vigilance in young baboons: Effects of habitat, age, sex and maternal rank on glance rate. Animal Behaviour, 47, 749-755.

Arenz, C. L. 1997. Handling fox squirrels: ketamine-hydrochloride vs. a simple restraint. Wildlife Society Bulletin, 25, 107-109.

Arenz, C. L. and Leger, D.W. 1997. The antipredator vigilance of adult and juvenile thirteen-lined ground squirrels (Sciuridae: Spermophilus tridecemlineatus): visual obstruction and simulated attacks with a hawk model. Ethology, I 03, 945-953.

Armitage, K. B. and Chiesura, C. M. 1994. Time and wariness in yellow-bellied marmots. Ibex Journal of Mountain Ecology, 2, I-8.

Bachman, G. C. 1993. The effect of body condition on the trade-off between vigilance and foraging in Belding's ground squirrels. Animal Behaviour, 46, 233-244.

Bednekoff, P. A. and Ritter, R. 1994. Vigilance in Nxai pan springbok, Antidorcas marsupialis. Behaviour, I 29, I-I I.

Betts, B. J. 1976. Behaviour in a population of Columbian ground squirrels, Spermophilus columbianus. Animal Behaviour, 24, 652- 680 .

Blumstein, D. T. 1996. How much does social group size influence golden marmot vigilance? Behaviour, 133, II33-1151.

Burger, J. and Gochfeld, M. 1994. Vigilance in African mammals: Differences among mothers, other females and males. Behaviour, I3 I, 153-169.

Carey, H.V. and Moore, P. 1986. Foraging and predation risk in yellowbellied marmots. American Midland Naturalist, I l 6, 267- 275.

Colagross, A. M. L. and Cockburn, A. 1993. Vigilance and grouping in the eastern grey kangaroo, Macropus giganteus. Australian Journal of Zoology, 4I, 325-334.

De Ruiter, J. R. 1986. The influence of group size on predator scanning and foraging behaviour of wedge-capped capuchin monkeys (Cebus olivaceus). Behaviour, 98, 240-278.

Elgar, M. A. 1989. Predator vigilance and group size in mammals and birds: A critical review of the empirical evidence. Biological Reviews of the Cambridge Philosophical Society, 64, 13-33.

Evans, F. C. 195I. Notes on a population of the striped ground squirrel (Citellus tridecemlineatus) in an abandoned field in southeastern Michigan. Journal of Mammalogy, 32, 437-449.

Fragaszy, D. M. 1990. Sex and age differences in the organization of behaviour in wedge-capped capuchins, Cebus olivaceus. Behavioural Ecology, I, 8I-94.

Heathcote, C. F. 1987. Grouping in eastern grey kangaroos in open habitat. Australian Wildlife Research, I4, 343-348.

Higgins, L. C. and Stapp, P. 1997. Abundance of thirteen-lined ground squirrels in shortgrass prairie. Prairie Naturalist, 29, 25-37.

Hoffman, C. M., Flory, G. S., and Alberts, J. R. 1999. Ontogenetic adaptation and learning: a developmental constraint in learning for a thermal reinforcer. Developmental Psychobiology, 34, 73- 86.

Holekamp, K. E. and Nunes, S. 1989. Seasonal variation in body weight, fat, and behavior of California ground squirrels (Spermophilus beecheyi). Canadian Journal of Zoology, 67, 1425-1433.

Holmes, W. G. 1984. Predation risk and foraging behavior of the hoary marmot in Alaska. Behavioral Ecology and Sociobiology, I 5, 293-30I.

Jones, J. K. Jr, Armstrong, D. M., and Choate, J. R. 1985. Guide to the Mammals of the Plains States. Lincoln: University of Nebraska Press.

Leger, D.W. and Didrichsons, I.A. 1994. An assessment of data pooling and some alternatives. Animal Behaviour, 48, 823-832.

Leger, D.W., Owings, D. H., and Coss, R. G. 1983. Behavioral ecology of time allocation in California ground squirrels (Spermophilus beecheyi): microhabitat effects. Journal of Comparative Psychology, 97, 283-291.

Lima, S. L. 1990. The influence of models on the interpretation of vigilance. In: Interpretation and Explanation in the Study of Animal Behaviour: Vol. 2. Explanation, Evolution and Adaptation (Ed. by M. Bekoff and D. Jamieson), pp. 246-267. Boulder, Colorado:Westview Press.

Loughry, W. J. 1992. Ontogeny of time allocation in black-tailed prairie dogs. Ethology, 90, 206-224.

Loughry, W. J. 1993. Mechanisms of change in the ontogeny of blacktailed prairie dog time budgets. Ethology, 95, 54-64.

Loughry, W. J. and McDonough, C. M. 1989. Calling and vigilance in California ground squirrels: age, sex and seasonal differences in responses to calls. American Midland Naturalist, I 2 I, 3 I2-321.

McCarley, H. 1966. Annual cycle, population dynamics and adaptive behavior of Citellus tridecemlineatus. Journal of Mammalogy, 47, 294-316.

McDonough, C. M. and Loughry, W. J. 1995. Influences on vigilance in nine-banded armadillos. Ethology, I00, 50-60.

MacHutchon, A. G. and Harestad, A. S. 1990. Vigilance behaviour and use of rocks by Columbian ground squirrels. Canadian Journal of Zoology, 68, I428-1432.

Melchior, H. R. and Iwen, F.A. 1965. Trapping, restraining and marking Arctic ground squirrels for behavioral observations. Journal of Wildlife Management, 29, 67I-678.

Metcalfe, N. B. and Furness, R. W. 1984. Changing priorities: the effect of premigratory fattening on the trade-off between foraging and vigilance. Behavioral Ecology and Sociobiology, I 5, 203-206.

Prins, H. H.T. and lason, G. R. 1989. Dangerous lions and nonchalant buffalo. Behaviour, 108, 262-296.

Quenette, P.-Y. 1990. Functions of vigilance behavior in mammals: a review. Acta Oecologica, I I, 80 I-8I8.

Roberts, G. 1996. Why individual vigilance declines as group size increases. Animal Behaviour, 5 I, I077-1086.

Rongstad, O. J. 1965. A life history study of thirteen-lined ground squirrels in southern Wisconsin. Journal of Mammalogy, 46, 76-87.

Schall, A. and Ropartz, P. 1985. Le comportement de surveillance chez le daim (Dama dama). Comptes Rendus à l'Académie des Sciences, Paris, 30I, 73I-736.

Sibly, R. M., Collett, D., Promislow, D. E. L., Peacock, D. J., and Harvey, P. H. 1997. Mortality rates of mammals. Journal of Zoology, 243, I-12.

Sih, A. 1980. Optimal behavior: Can foragers balance two conflicting demands? Science, 21 0, 104 I-1043.

Streubel, D. P. and Fitzgerald, J. P. 1978. Spermophilus tridecemlineatus. Mammalian Species, I 03, I-5.

Tilson, R. 1980. Klipspringer (Oreotragus oreotragus) social structure and predator avoidance in a desert canyon. Madoqua, I I, 303-3I4.

Wistrand, H. 1974. Individual, social, and seasonal behavior of the thirteen-lined ground squirrel (Spermophilus tridecemlineatus). Journal of Mammalogy, 55, 329-347.

Ydenberg, R. C. and Dill, L. M. 1986. The economics of fleeing from predators. Advances in the Study of Behavior, 16, 229-249. 